\title{
EN BÚSQUEDA DE LA VOLUNTAS \\ LEGISLATORIS: ACTOS DE COMPETENCIA \\ DESLEAL CONTRA LOS CONSUMIDORES \\ Y LEGITIMACIÓN PROCESAL \\ DEL MINISTERIO PÚBLICO EN CUBA*
}

LUIS PÉREZ OROZCO**

\section{RESUMEN}

La regulación jurídica de la represión a la competencia desleal en Cuba es una materia totalmente novedosa. La participación del fiscal en el proceso donde se ventilen afectaciones provocadas por esos actos introduce al Ministerio Público en una esfera de actuación sin precedentes. Este artículo pretende explicar la intervención procesal de la Fiscalía para demandar por afectaciones derivadas de actos de competencia desleal que infringen derechos de propiedad industrial contra los consumidores. El estudio se hizo tomando como referencia la más actualizada doctrina sobre el Derecho Procesal y su incidencia en la tramitación judicial de los actos desleales en el comercio, pero se hace mayor énfasis en la protección al consumidor y las particularidades que significa para el Ministerio Público cubano. Como resultado del análisis hecho se concluyó que son múltiples las jurisdicciones competentes para atender los litigios sobre competencia desleal que infringen derechos de propiedad industrial contra los consumidores. Además, se requiere la especialización del fiscal encargado de estos asuntos y urge que la ley procedimental sea modificada en aras de garantizar una tutela adecuada a los intereses perjudicados, en especial cuando estos pertenecen a grupos vulnerables de la relación de consumo.

\footnotetext{
* El artículo es resultado del proyecto de investigación "Estrategias preventivas en el contexto de actualización del modelo socioeconómico cubano”, dirigido por la Dr. C. Yairis Arencibia Fleitas, Profesora de Derecho Civil y Derecho de Obligaciones y Vicedecana de Investigación y Posgrado de la Facultad de Ciencias Sociales y Humanidades de la Universidad de Matanzas, Cuba.

** Licenciado en Derecho por la Universidad de Matanzas, Cuba. Profesor de Derecho de la Universidad de Matanzas de Cuba. País: Cuba. Identificador ORCid: https://orcid. org/0000-0002-4289-0051. Matanzas (Cuba). Contacto: luisperezorozco@yandex.com. Fecha de recepción: 10 de julio de 2020. Fecha de aceptación: 26 de agosto de 2020. Para citar el artículo: Pérez Orozco, Luis. "En búsqueda de la voluntas legislatoris: actos de competencia desleal contra los consumidores y legitimación procesal del Ministerio Público en Cuba", en Revista de la propiedad inmaterial n. ${ }^{\circ} 30$, Universidad Externado de Colombia, julio 2020-diciembre 2020, pp. 199-228. DoI: https://doi.org/10.18601/16571959.n30.08
} 
Palabras clave: Competencia desleal; Legitimación procesal; Ministerio Público.

\author{
Searching for Voluntas Legislatoris: \\ The Unfair Competition against Consumers \\ and the Ability to sue of Attorney General's Office in Cuba
}

\title{
ABSTRACT
}

The legal regulation of the repression of unfair competition in Cuba is a totally new subject. The participation of the prosecutor in the process where the effects caused by these acts are aired, introduces the Public Ministry into an unprecedented sphere of action. This paper aims to explain the procedural intervention of the Attorney General's Office to sue for damages derived from acts of unfair competition that infringe industrial property rights against consumers. The study was made taking as reference the most up-to-date doctrine on Procedural Law and its incidence in the judicial processing of unfair acts in commerce, but greater emphasis is placed on consumer protection and the particularities that it means for the Cuban Public Ministry. As a result of the analysis, it was concluded that there are multiple competent jurisdictions to deal with disputes about unfair competition that infringe industrial property rights against consumers. In addition, the specialization of the prosecutor in charge of these matters is required and it is urgent that the procedural law be modified in order to guarantee adequate protection for the harmed interests, especially when they belong to vulnerable groups in the consumer relationship.

Keywords: Unfair Competition; Ability to sue; Attorney General's Office.

"La teoría es fundamental para conocer el porqué y ver cuál ha sido el tránsito de la institución que tanto estamos defendiendo. Eso es sumamente importante, porque forma parte del bagaje cultural del fiscal, que no debe ser solo conocer la Ley como texto, sino conocer por qué se crea, los fines, su proyección, su campo futuro...”. Julián Sebastián León Morel.

\section{INTRODUCCIÓN}

La necesidad de satisfacer los intereses cada vez más crecientes de usuarios y consumidores propicia la confluencia en el mercado de diferentes actores económicos capaces de ofrecer ofertas disímiles para productos del mismo tipo. En este proceso es vital la diferenciación de unos empresarios con otros y la constante creatividad para superar a la competencia, a la vez que se pretende adquirir y fortalecer clientela. Además, a esa dinámica se le añade la transformación de la naturaleza del proceso competitivo a partir de la evolución tecnológica y la globalización. 
EN BÚSQUEDA DE LA VOLUNTAS LEGISLATORIS: ACTOS DE COMPETENCIA DESLEAL CONTRA LOS CONSUMIDORES Y LEGITIMACIÓN PROCESAL DEL MINISTERIO PÚBLICO EN CUBA

Luego, la vigencia de las ventajas comerciales se reduce considerablemente si los empresarios no desarrollan sus fuentes. Los derechos de propiedad intelectual y su expresión en activos fijos intangibles devienen en factor estratégico para mejorar el posicionamiento en el mercado; sin embargo, su valor disminuirá sin la debida protección. Entonces, las normas jurídicas son las encargadas de amparar las creaciones intelectuales técnicas y comerciales mediante un sistema de reglas, derechos y obligaciones que integran la denominada Propiedad Industrial.

El amparo brindado por esta disciplina no constituye un fin por sí mismo, sino un medio para fomentar la actividad creativa, la industrialización, las inversiones y las actividades comerciales honradas. Además, persigue, entre otros fines, contribuir al desarrollo tecnológico y económico, distinguir bienes y servicios entre los empresarios, arraigar clientes con base en el reconocimiento y prestigio, así como determinar las pautas para un trato justo y ordenado en el comercio. Sin embargo, dichas facultades pueden ser violentadas mediante actos desleales y provocar daños o perjuicios a los titulares de esas creaciones y sus destinatarios. En este sentido, es viable la tutela procesal para resolver los litigios suscitados al respecto. La legitimación ante los tribunales competentes depende de las soluciones propias que cada ordenamiento legal establezca, pero en general pueden encontrarse como sujetos activos a los consumidores y sus formas asociativas, diferentes instancias gubernamentales, dígase Procuradurías, Superintendencias o Ministerios Públicos.

En Cuba, el Decreto-Ley n. ${ }^{\circ} 337$ de 2018 dispone la legitimación procesal de la Fiscalía frente a aquellos actos de competencia desleal que afecten el orden, la moral, los intereses públicos o de los consumidores. De este modo, se introduce un área novedosa para este órgano estatal y el sistema nacional de la propiedad intelectual. Desde luego, no existen estudios previos argumentativos de las particularidades procesales que para la Fiscalía suscitarán los debates litigiosos vinculados a actos desleales en el comercio.

En aproximación a esta temática, las investigaciones patrias son encabezadas por Dánice Vázquez De Alvaré y Johana Odriozola Guitart. Se suma la cátedra sentada por Marta Moreno Cruz en cuestiones de Propiedad Industrial. En ese universo doctrinal, no existen investigaciones que sitúen la dinámica de trabajo judicial del Ministerio Público (institución estatal con una fuerte carga de asuntos penales) en los presupuestos teóricos y fácticos de la competencia desleal.

Por tanto, este artículo tiene como objetivo principal explicar la intervención procesal de la Fiscalía para demandar por afectaciones a consumidores derivadas de actos de competencia desleal contra derechos de propiedad industrial. Además, son objetivos específicos identificar la voluntad del legislador al incluir la participación del fiscal en el Decreto-Ley n. ${ }^{\circ} 337$ y reconocer la interrelación de las normas procesales con las de Derecho sustantivo sobre competencia desleal. El análisis hecho por este autor no abarca la concurrencia de proveedores extranjeros en el mercado nacional ni la prestación de servicios on line, pues ambas cuestiones 
implican dificultades jurídicas adicionales que desbordan la finalidad principal de esta investigación.

Se utilizaron como métodos: el deductivo-inductivo: permitió ir de lo general (el examen de disposiciones legales y resoluciones jurisdiccionales foráneas y nacionales) a lo particular (artículos de esas disposiciones y párrafos específicos). Además, cuando se aplica una norma jurídica a la solución de un caso se hizo uso de este. También resultó necesario el método análisis-síntesis para determinar las características más acuciantes de la competencia desleal como objeto investigado, al implicar una abstracción mediante la cual se segmentó en aquellas cualidades que lo representen. El método de análisis histórico contribuyó a la comprensión total del objeto de estudio y brindó la visión de la transición en el tiempo de la norma y la jurisprudencia. Sobre esta última, se tomaron algunos pronunciamientos como referencia para fundamentar el análisis, pero no se trata de la aplicación del método de Derecho comparado en sentido estricto. Al respecto, el autor explica que se han seleccionado fragmentos de sentencias de diversos países de Iberoamérica por ser la región más afín cultural y jurídicamente a la sociedad y sistema legal cubanos. Estas resoluciones judiciales, a pesar de que no constituyen fuente de Derecho en Cuba, sientan pautas jurisprudenciales y son representativas de lo mejor de los pronunciamientos que han hecho algunos tribunales. Por tanto, se convierten en un referente casi obligado como orientador de futuras transformaciones en el ordenamiento jurídico nacional.

\section{FUNDAMENTOS TEÓRICO-DOCTRINALES}

\section{DE LA COMPETENCIA DESLEAL COMO INSTITUCIÓN JURÍDICA}

Cualquier estudio respecto al tema debe partir de algunos conceptos que son necesarios para comprender mejor el planteamiento central de esta investigación.

Mercado, en economía, es cualquier conjunto de transacciones de procesos o acuerdos de intercambio de bienes o servicios entre individuos o asociaciones de individuos, de ahí que se generen relaciones comerciales entre estos. El mercado se considera que puede ser de competencia perfecta o imperfecta, y en esta investigación se asume como competencia a la situación en la cual los agentes económicos tienen la libertad de ofrecer bienes y servicios en el mercado, y de elegir a quién compran o adquieren estos bienes y servicios.

La competencia perfecta es la situación del mercado en la que el número de vendedores y compradores es muy grande, de tal forma que ninguno de ellos ejerce una influencia perceptible sobre el precio. En esas condiciones, todas las empresas enfrentan una curva de demanda perfectamente elástica. En un mercado de competencia perfecta, para el vendedor y el comprador, individualmente considerados, no hay decisiones que tomar con respecto al precio; cada uno de ellos es un precio aceptante, es decir que aceptan el precio establecido por el mercado sin tratar de influir en él. Por su parte, la competencia imperfecta en una definición amplia es 
EN BÚSQUEDA DE LA VOLUNTAS LEGISLATORIS: ACTOS DE COMPETENCIA DESLEAL CONTRA LOS CONSUMIDORES Y LEGITIMACIÓN PROCESAL DEL MINISTERIO PÚBLICO EN CUBA

cualquier tipo de mercado distinto a la competencia perfecta. Para especificar la definición anterior se puede decir que la competencia imperfecta es una situación de mercado en la que no existe competencia perfecta porque al menos un vendedor o un comprador es suficientemente grande para influir en el precio de mercado ${ }^{1}$.

Uno de esos mecanismos que incide en la regulación del mercado es la represión a los actos de competencia desleal. Según la Corte Constitucional de Colombia: "constituye competencia desleal todo acto o hecho que se realice en el mercado con fines concurrenciales, cuando resulte contrario a las sanas costumbres mercantiles, al principio de buena fe comercial, a los usos deshonestos en materia industrial o comercial, o bien cuando esté encaminado a afectar o afecte la libertad de decisión del comprador o consumidor, o el funcionamiento concurrencial del mercado" 2 . En síntesis, la competencia desleal es todo acto ilícito contrario a la buena fe en la concurrencia comercial ${ }^{3}$.

Por tanto, para su configuración teórica requiere que el acto se realice en el comercio y sea contrario a la buena fe concurrencial. En nada influye la existencia o no de una relación de competencia entre los sujetos intervinientes. El elemento clave es el fenómeno de la concurrencia, entendido este como el ejercicio de una actividad análoga por empresarios diferentes, un criterio sostenido por el Tribunal Supremo de España en su jurisprudencia reciente. El máximo órgano ibérico sentenció que para la configuración de la finalidad concurrencial es suficiente que el acto o el comportamiento fuese idóneo para influir en la estructura del mercado o perjudicase la posición simultánea de una de las partes, al beneficiar objetivamente, al menos de forma potencial, la posición de otros operadores económicos concurrentes en el mercado ${ }^{4}$.

La función principal de la competencia desleal es la protección a los bienes jurídicos constituidos por las relaciones sociales o sus elementos integrantes, que, por interés general, son protegidas por medio del Derecho de la competencia frente

1 Apoyado en Tamames, R., Diccionario de Economía, Segunda edición (revisada), Madrid, Alianza Editorial, 1989, pp. 62 y 149-151.

2 Véase Corte Constitucional de Colombia, Sentencia C-535/97, de 23 de octubre de 1997, [en línea], disponible en: http://www.corteconstitucional.gov.co/ relatoria/1997/c-535-97.htm [consultado el 10 de abril de 2020].

3 Arboleda, A. M., "Beneficios y perjuicios de la estrategia de imitación”, Estudios Gerenciales, n.o 30, 2014, pp. 145-152, e Inostroza SÁEz, M., "El ilícito concurrencial general en la Ley n. 20.169 sobre Competencia Desleal”, Ius et Praxis, año 23. n. ${ }^{\circ}$, 2017, pp. 21-66.

4 “(...) Lo relevante es si los comportamientos denunciados y acreditados son idóneos para influir en el mercado, en concreto porque mermen la competitividad de la sociedad demandante en beneficio de sus competidores (...) Cabe presumir la finalidad concurrencial no solo cuando se beneficia objetivamente la posición de los propios demandados, autores de los comportamientos, sino también cuando se beneficia la posición de otros operadores económicos que concurren en ese mercado. De ahí que, como hemos advertido antes, no sea necesario que exista una relación de competencia entre los sujetos activos, demandados, y el sujeto pasivo, la sociedad demandante". Véase Tribunal Supremo de España, Sala de lo Civil, Sentencia 59, de 29 de enero de 2019, [en línea], disponible en: https://www.iberley.es/jurisprudencia/sentencia-civil-n-59-2019-ts-salacivil-sec-1-rec-1514-2016-29-01-2019-47983956. [consultado el 14 de abril de 2020]. 
a los ataques o amenazas materializados por comportamientos considerados contrarios a la buena fe comercial. También busca promover la observancia y desarrollo de comportamientos ajustados a dicho sistema de relaciones. En ese sentido se pronunció el Tribunal de Justicia del Estado Río Grande del Norte en Brasil: "Nas sociedades empresariais, faz-se mister prestigiar valores que devem ser especialmente preservados no direito econômico, em especial para garantir a celeridade e a segurança nos negócios jurídicos realizados, como, também, para assegurar o exercício da atividade desenvolvida, por razões de ordem econômica, que impõem a manutençāo da produção de riquezas, do interesse dos trabalhadores, do fisco e da própria sociedade civil's.

Luego, el objeto de esa relación jurídica, a criterio del autor, está conformado por el Derecho de la competencia. Dicha categoría se define como el sistema de normas y principios regulatorios de la actividad comercial con el objetivo de que predomine la buena fe entre los competidores.

El autor coincide con Reveco Úrzua cuando afirma que el ataque a una posición de mercado será lícito si lo justifica la mayor eficiencia del competidor. Sin embargo, no lo será cuando sea fruto de la habilidad de interferir en los negocios ajenos y como consecuencia los mecanismos del libre mercado no operarán adecuadamente y las ganancias de algunos agentes se obtendrán de manera ilícita. Estas fallas de mercado son las que la norma de competencia desleal busca superar, al otorgarle acciones protectoras de sus intereses a los sujetos ${ }^{6}$.

Los intereses en juego serán los provenientes de todos aquellos destinatarios de las normas de competencia desleal y de ahí la existencia de una multiplicidad de sujetos. Los mismos pueden clasificarse como activos o pasivos según sea el desempeño en el comercio, y a su vez deslindarse en titulares o no de los derechos de propiedad industrial violentados. Por tanto, se colige que como personas jurídicas intervienen en esta dinámica las empresas (proveedores, productores y prestadores), el Estado y las diferentes formas asociativas (Consejos Reguladores de la reputación y las organizaciones de consumidores). Mientras, las personas naturales pueden ser los empresarios mercantiles, creadores, consumidores y usuarios ${ }^{7}$. Como resultado, se observa la estrecha relación y transversalidad entre la Propiedad Industrial y las regulaciones del Derecho del consumidor.

5 Tribunal de Justiça do Estado do Rio Grande do Norte, Brasil, Apelação Cível 2017.003523-2, de 12 de diciembre de 2016, [en línea], disponible en: http://www.ritteremoraes.com.br/wp-content/uploads/2018/06/Apela\%C3\%A7\%C3\%A3o-C\%C3\%ADveln\%C2\%B0-2017.003523-2.pdf. [consultado el 25 de marzo de 2020].

6 Reveco Urzúa, R. y Padilla Parot, R., "Derecho de la libre competencia”, en Revista Chilena de Derecho Privado, n. ${ }^{\circ} 28,2017$, pp. 376-377.

7 "Es posible observar que tanto en la jurisprudencia como en la dogmática no existe una opinión común acerca de la delimitación del ámbito subjetivo de aplicación de la Ley de competencia desleal, extremo que es de interés, debido a que determina en muchas ocasiones la estimación o el rechazo de la acción deducida”. A partir de distinguir quién es considerado como sujeto se derivaría la facultad de pedir tutela ante los órganos jurisdiccionales. Véase Bernet PÁez, M. A., "El ámbito subjetivo de aplicación de la Ley de competencia desleal”, Ius et praxis, año 24, n. ${ }^{\circ} 2,2018,437$. 
En todos los casos, la causa de la relación jurídica yace en los actos desleales. Para su estudio, la doctrina acude a una clasificación según el bien jurídico protegido. Se distingue en actos contrarios a los competidores (denigración, imitación, aprovechamiento injusto, divulgación de información en régimen de confidencialidad e inducción a la infracción contractual), los consumidores (confusión, engaño, comparación y promoción de ventas) y el mercado (violación de normas, venta a pérdidas y discriminación $)^{8}$.

Ergo, la competencia desleal genera una relación jurídica obligatoria, en virtud de la cual el causante del daño o perjuicio está obligado a resarcirlos. Si bien ellos son innecesarios para apreciar la existencia de un acto desleal, el enfoque teórico que se adopte conducirá al debate inevitablemente ${ }^{9}$. Asimismo, cada ordenamiento jurídico reconocerá determinadas acciones al interesado de acudir al órgano jurisdiccional competente para reclamar la actividad de este, en demanda de tutela jurídica frente a otro sujeto si considera que se han violado sus derechos. En la gama de facultades concedidas están la cesación o prohibición del acto, el resarcimiento de daños y perjuicios, la remoción de los efectos, la declaración de deslealtad, la corrección de seudoinformaciones y la acción civil de enriquecimiento indebido.

\section{LOS ACTOS DE REPRESIÓN A LA COMPETENCIA \\ DESLEAL EN EL SISTEMA DE DERECHO CUBANO}

Para el sistema jurídico y económico de Cuba, el mercado existe y actúa con independencia de que sea reconocido o no, tanto en el escenario nacional como en el internacional. Los actores económicos (empresas estatales, unidades presupuestadas, empresas mixtas y privadas, cooperativas y trabajadores por cuenta propia) interactúan en el mercado como ofertantes y demandantes de bienes y servicios. La dirección planificada de la economía tiene en cuenta el mercado, lo regula y enmarca sus espacios de actuación dentro de las finalidades estratégicas. En el país,

8 Para una descripción exhaustiva de cada uno de los actos de competencia desleal Véase Vázquez de Alvaré, D., La competencia desleal en el mercado cubano, 2. ${ }^{a}$ ed., La Habana, Ediciones onBC, 2016, pp. 78-103.

9 "Los efectos desde las teorías, muestran diferentes facetas. Así, desde la teoría de la protección de la personalidad, se afectan los derechos de las personas en general y en especial, de los competidores y consumidores. Frente a la teoría del abuso del derecho, se observa la necesidad de proteger el equilibrio entre los derechos individuales y los colectivos, de tal forma, que la convergencia de ellos permite el restablecimiento de los derechos con la función social, ya que estos actos alteran el equilibrio y la libertad competitiva en el comercio, precisamente por el desborde de los límites personales. Conforme a la teoría del acto excesivo, se convierte en un fenómeno que extralimita las fronteras de lo legal y sus efectos son nocivos para la sociedad. En sala de la teoría de la protección a la hacienda, se afectan los derechos porque se desvía la finalidad de las normas y se alteran la concordia social, lo mismo que la igualdad y la propiedad privada. Frente a la teoría de la imputación objetiva, se conjuga con la posición funcionalista, y por lo tanto, solo basta lo descrito en la ley y la posición de garante, sin que sea necesario que parezca el daño materializado, por el potencial peligro (...)”. Véase Negrete Doria, E. F., "Aspectos procesales de la competencia desleal", Justicia Juris, vol. 12, n.o 1, 2016, p. 58. 
el mercado regulado funciona como contexto coordinador de las innumerables interacciones que se producen entre los múltiples actores económicos.

La ideología neoliberal en su visión extrema proclama que la "mano invisible" de la acción del mercado debe conducir a resultados económicos socialmente óptimos, a través de la libre competencia a medida que los individuos actúan guiados esencialmente por el interés personal. Según la concepción que Cuba asume el "libre mercado" no existe realmente; no hay competencia perfecta; existen los monopolios y oligopolios que controlan los mercados. La incapacidad y carácter antagónico de las leyes del mercado neoliberal en términos de justicia, equidad e inclusión social, protección del medioambiente y desarrollo sostenible con visión a largo plazo son evidentes. En consecuencia, se enmarca y regula el mercado dentro de sus finalidades estratégicas mediante diferentes medios, como parte del perfeccionamiento del sistema de dirección planificada de la economía, de modo que sus leyes no desempeñan el papel rector en su funcionamiento ${ }^{10}$.

El Estado cubano implementa actualmente un conjunto de políticas públicas integrales en torno a la consecución de metas comerciales para el beneficio nacional y el cumplimiento de compromisos internacionales. Se reconoce que tanto el Estado como el gobierno tienen entre sus funciones fundamentales regular los mecanismos del mercado, los intereses individuales y colectivos mediante instrumentos económicos de dirección, así como la publicidad. Se busca estimular el desarrollo y el fomento de un consumo razonable y sostenible. Es admitida la importancia de las políticas comerciales y normas jurídicas para regular la competencia, a la vez que se estructura un sistema integral y eficaz de protección a los consumidores, que incluye, entre otros elementos, la información objetiva sobre las cualidades y precios del producto o servicio ${ }^{11}$.

La materialización de ese interés estatal encuentra su mayor exponente en lo preceptuado por la Carta Magna, al tutelar como bien de rango constitucional a los derechos de propiedad intelectual ${ }^{12}$. Su garantía institucional radica en el sistema nacional de la propiedad intelectual y la Oficina Cubana de la Propiedad Industrial, los que tienen como principio "contrarrestar el ejercicio abusivo de los derechos de propiedad intelectual que se adquieran y las prácticas que limiten de manera justificada el comercio"13.

$\mathrm{Al}$ mismo nivel y en estrecha relación con los derechos de propiedad industrial se ubica el Derecho al consumo, por lo que atiende, de este modo, tanto a

10 Véase Castellanos Rodríguez, R.; Baute Rosales, M.: Chang Ramírez, J. A. y Cantero Jiménez, I., "Compatibilidad y límites entre mercado y socialismo: reto teórico-práctico en la conceptualización y actualización del modelo económico cubano”, en Revista Cientifica, Cultura, Comunicación y Desarrollo, vol. 5, n. o 1, 2020, pp. 85-90.

11 Apoyado en Bonachea García, A. E., La política de competencia en Cuba. Tratamiento doctrinal y legal, Trabajo de Diploma, Universidad Central Martha Abreu de Las Villas, Cuba, 2013.

12 Artículo 62 de la Constitución de la República de Cuba de 2019.

13 Véase artículo 2, inciso c) del Decreto n. ${ }^{\circ}$ 343, de 2018. 
EN BÚSQUEDA DE LA VOLUNTAS LEGISLATORIS: ACTOS DE COMPETENCIA DESLEAL CONTRA LOS CONSUMIDORES Y LEGITIMACIÓN PROCESAL DEL MINISTERIO PÚBLICO EN CUBA

los intereses colectivos como a los difusos ${ }^{14}$. Dicha clasificación no es una mera división doctrinal, pues de ella dependerá el alcance de los efectos provocados por los actos desleales en el comercio.

Los intereses colectivos se corresponden a un conjunto de sujetos determinados, más o menos numeroso, entre los que puede existir un vínculo jurídico previo o que sin existir este es evidente su afectación por idéntico hecho dañoso, de modo que puede determinarse a los afectados. En cambio, los intereses difusos atañen a un conjunto de sujetos absolutamente indeterminados, sin perjuicio de que no exista entre ellos vínculo jurídico alguno; por consiguiente, la afectación a todos ellos deriva solo de razones eventuales de hecho (posibles consumidores de un mismo producto, destinatarios de una campaña de publicidad ${ }^{15}$, entre otros). Supone especialmente la imposibilidad de identificar a los sujetos implicados y la inexistencia de un ente capaz de afirmar que agrupa a todos aquellos sujetos o tiene la representatividad como organización.

Su respaldo se dispone mediante la Resolución n. ${ }^{\circ} 54$ de 2018 del Ministerio de Comercio Interior, que estructura el sistema de protección a los consumidores. De la gama de prerrogativas reconocidas al consumidor está recibir protección contra la publicidad comercial falsa o engañosa y práctica desleal de los proveedores ${ }^{16}$. Las prácticas desleales en el comercio cubano actualmente se regulan mediante el Decreto-Ley n. ${ }^{\circ} 337$ de $2018^{[17]}$ y son concebidas como todo acto contrario a los usos y prácticas honestas en la industria y el comercio, siempre que produzcan o puedan producir efectos sustanciales en la promoción y ofrecimiento de productos o servicios en el mercado nacional a favor del comisor de las prácticas tipificadas o de un tercero.

Es tipificado como competencia desleal todo acto susceptible de causar una confusión, por cualquier medio, respecto al establecimiento, productos o actividad industrial o comercial de un competidor; las aseveraciones falsas, en el ejercicio del comercio, capaces de desacreditar el establecimiento, los productos o la actividad industrial o comercial de un competidor; las indicaciones o aseveraciones cuyo empleo, en el ejercicio del comercio, pudieren inducir al público a error sobre la naturaleza, el modo de fabricación, las características, la aptitud en el empleo, la

14 Artículo 78 de la Constitución de la República de Cuba de 2019.

15 "Que recayendo en el actor la carga probatoria, es del caso que la rendida resulta insuficiente y aun contraria a sus intereses para esclarecer el daño material por daño emergente, ya que si bien se agregaron facturas por marketing y publicidad, no se cuenta con otros antecedentes que permitan vincular de modo causal a los efectos de la competencia desleal los gastos publicitarios en que incurrió, ni es dable presumir por cuanto tiempo debió reforzar ese marketing para revertir las secuelas de la conducta sancionada”. Véase Corte Suprema de Chile, Cuarta Sala, Sentencia s. n., de 23 de julio de 2012, dictada por la Jueza Titular Rocío Pérez Gamboa, [en línea] Disponible en: https:// www. 24 horas.cl/incoming/article 413299 .ece/BINARY/Fallos\%20por\%20 competencia\% 20 desleal [consultado el 10 de abril de 2020].

16 Confróntese Resuelvo Sexto, inciso b) de la Resolución n. ${ }^{\circ} 54$ de 2018.

17 Véase artículo 2.1 del Decreto-Ley n. ${ }^{\circ} 337$ de 2016. 
cantidad de los productos, el origen de los productos, su lugar de procedencia o la identidad del productor, fabricante o comerciante.

La legislación cubana asume la misma posición de la jurisprudencia española al prescindir de la relación de competencia entre los actores económicos concurrentes del mercado. Respecto a la configuración de un daño para calificar el acto, se concluye que no es necesario como causa. El concepto iusprivatista del daño resarcible se abandona, abriendo paso a una tendencia diferente, publicística, de tipo preventiva, donde se busca principalmente la paralización de los efectos perjudiciales.

Se pueden solicitar en particular las acciones siguientes: el cese del acto en ejecución y la prohibición de su reiteración; la prohibición del acto si aún no se ha ejecutado y el apercibimiento de que en lo sucesivo se abstenga de realizar este u otros con el mismo propósito; la declaración de la deslealtad del acto si la afectación creada por este subsiste; el restablecimiento de la situación existente antes de que aconteciere la vulneración ocasionada por el acto desleal y el cese inmediato de los efectos producidos por ese acto; la rectificación de las informaciones engañosas, incorrectas o falsas, y el resarcimiento por los daños y perjuicios ocasionados a causa del acto desleal, si se comprueba dolo o culpa del comisor.

Están legitimados para interponer demandas las personas naturales y jurídicas que participen en el mercado, cuyos intereses económicos resulten directamente perjudicados o amenazados por una práctica desleal; las asociaciones legalmente reconocidas cuando resulten afectados los intereses de alguno de sus miembros, y el fiscal, cuando puedan ser afectados directa o indirectamente el orden, la moral, los intereses de los consumidores u otros intereses públicos.

Para la doctrina cubana, las normas represoras de la competencia desleal tienen carácter supletorio o subsidiario frente a las disposiciones jurídicas específicas de la Propiedad Industrial. Se trata de un criterio que más recientemente sostiene Ivette Matamoros Massip: "El nuevo Decreto-Ley de protección contra actos desleales en materia de propiedad industrial constituye un hito en la legislación cubana pues es una norma pionera en regular la materia cuya principal cualidad es el dotar de herramientas legales concretas a los empresarios para llevar a cabo la defensa de sus derechos de PI (propiedad intelectual) como vía alternativa o complementaria a la Legislación de Propiedad Industrial vigente (...)"18. Por ejemplo, en casos de violaciones del Derecho marcario, se acude primero a la vía administrativa. Así se complementa la protección otorgada mediante el registro de derechos exclusivos de explotación. Pero como en Cuba los tipos específicos previstos en la ley son insuficientes respecto a lo regulado en el Decreto-Ley n. ${ }^{\circ} 337$, su ámbito de

18 Matamoros Massip, Ivette: Decreto-Ley 337 de protección contra las prácticas desleales en materia de propiedad Industrial en Cuba una norma jurídica necesaria en los nuevos tiempos que corren. Disponible en: https://www.academia.edu/37252003/ Decreto_Ley_337_proteccion_contra_las_practicas_desleales_en_materia_de_propiedad_industrial_en_Cuba 
EN BÚSQUEDA DE LA VOLUNTAS LEGISLATORIS: ACTOS DE COMPETENCIA DESLEAL CONTRA LOS CONSUMIDORES Y LEGITIMACIÓN PROCESAL DEL MINISTERIO PÚBLICO EN CUBA

aplicación es amplio y abarca casi todos los actos de competencia contrarios a los usos y costumbres del Derecho comercial.

\section{LA TUTELA JUDICIAL Y LA INTERVENCIÓN}

DEL MINISTERIO PÚBLICO EN LA SOLUCIÓN DE CONFLICTOS

\section{SOBRE COMPETENCIA DESLEAL DONDE SE INVOLUCREN}

\section{INTERESES COLECTIVOS DE CONSUMIDORES}

El Estado asegura, de conformidad con la ley, el acceso de las personas a los órganos judiciales a fin de obtener una tutela efectiva de sus derechos e intereses legítimos ${ }^{19}$. Por tanto, el elemento primigenio para entablar un pleito por presunta comisión de actos de competencia desleal parte de determinar la jurisdicción. Con el DecretoLey n. ${ }^{\circ} 337$ se coligen diferentes vías y a priori todas ellas conducentes a conocer de los litigios derivados de actos desleales en el comercio. Sin embargo, un análisis pormenorizado evidencia matices y dificultades latentes ante la inexistencia de un procedimiento especial o más adecuado para tramitar estos asuntos. La doctrina reconoce como atinado el proceso de amparo a tales efectos, pero su instrumentación en suelo patrio requiere su reconceptualización en la Ley de Procedimiento ${ }^{20}$, aunque ese debate no constituye objeto de estudio de la presente investigación.

La Carta Magna permite la reclamación por violación de los derechos refrendados en ella; sin embargo, al momento de redactar esta investigación todavía no había sido promulgada su legislación complementaria ${ }^{21}$. Que la Constitución reconozca tal posibilidad significa un paso de avance; no obstante, habría que esperar la posición finalmente adoptada por el legislador cubano en ese sentido.

Por otra parte, la jurisdicción en sede administrativa procede ante la demanda dirigida al tribunal contra las resoluciones de la Administración, como requisito procesal sine qua non, por la acción de un particular reclamando violaciones derechos subjetivos pre-constituidos a su favor, o por la acción de la propia Administración contra sus resoluciones firmes, que hayan creado derechos a favor de terceros y pretendan revocar ${ }^{22}$. El procedimiento definido por la Resolución 54 de protección al consumidor y la denegación, cancelación u oposición de derechos en la Oficina Cubana de la Propiedad Industrial, así como la impugnación de sus resoluciones, son algunos de los escenarios comunes en esta jurisdicción ${ }^{23}$.

19 Confróntese con artículo 92 de la Constitución de la República de Cuba de 2019.

20 El procedimiento de amparo y particularmente la experiencia argentina pueden resultar de referente para una futura reforma de las leyes procesales cubanas, al respecto Véase Verbic, F. y Oteiza, E., "La Corte Suprema argentina y la construcción del derecho constitucional a un debido proceso colectivo", en International Journal of Procedural Law, vol. 5, n. ${ }^{\circ} 1,2015$.

21 Confróntese con el artículo 99 de la Constitución de la República de Cuba de 2019.

22 Confróntese con el artículo 656.1 de la Ley n.o 7 de 1977.

23 La Resolución n. 54 de 2018 define como instancias protectoras de los derechos de los consumidores a la Dirección de Protección al Consumidor del Ministerio de Comercio Interior, la Dirección Estatal de Comercio de cada territorio, los Organismos 
En el ámbito civil, tanto el procedimiento ordinario como el sumario, son caminos posibles a seguir. Para conflictos de esta índole, la competencia estará dada por la cuantía de lo reclamado ${ }^{24}$. Se debe acotar que por el carácter tradicional y las reglas aplicables estas vías no son las más propicias, pues presuponen la actuación individual y concreta de una persona determinada, es decir, no se ajustan a la dinámica de los efectos derivados de la competencia desleal. Por ejemplo, si el quantum es mínimo, no motiva lo suficiente a cada consumidor como para promover un proceso y esto incide en las escasas demandas que se puedan promover; al respecto, Gordillo concluye que "la tendencia es permitir la ordinarización de un proceso sumario y la sumarización de un ordinario" 25 . La solución no sería crear un proceso para cada situación, sino de realizar variantes "que no hagan excesivamente gravosa al consumidor la reclamación, lo que debe traducirse en la vía judicial (y sin perjuicio de la existencia de medios alternativos de solución de conflictos) en procesos ágiles ${ }^{26}$.

También los pleitos derivados de actos de competencia desleal pueden ser atendidos por la jurisdicción laboral. El Código de Trabajo dispone como violación de la disciplina laboral, entre otras, a los hechos contrarios a las disposiciones vigentes en la entidad sobre la seguridad y protección de la información oficial y el secreto técnico o comercial. Luego de la imposición de algunas de las medidas disciplinarias estipuladas en el Code, el trabajador puede acudir al órgano de Justicia Laboral y si permaneciera inconforme reclamar ante el Tribunal Municipal Popular ${ }^{27}$.

En cambio, la jurisdicción económica es competente solo frente a determinados asuntos. En los Tribunales Provinciales serán atendidos solo los litigios que se susciten entre personas naturales o jurídicas, cubanas o extranjeras con representación o bienes o intereses en Cuba, con motivo de sus relaciones contractuales, salvo cuando se contraigan en la esfera de consumo de la población. En esta sede se conocen las causas de carácter extracontractual que surjan con motivo de los daños y perjuicios originados a terceros en su actividad económica por persona jurídica o natural, cubana o extranjera, en ocasión del desarrollo de su actividad

de la Administración Central del Estado y los Organismos Superiores de Desarrollo Empresarial y empresas cuando actúan en calidad de proveedores. Si bien dicha disposición ministerial omite referirse a la reclamación judicial por violación de los derechos de los consumidores, el autor considera que sí sería válida tal posibilidad si alguna de las instancias antes mencionadas comunicara su decisión mediante una Resolución. Luego el proceso administrativo sería el cauce para dilucidar el conflicto. Las normas jurídicas de la Propiedad Industrial en Cuba permiten expresamente acudir a las Salas de lo Civil y Administrativo ante diferentes circunstancias Véanse artículos 56.1, 119, 132.2 y Título v del Decreto-Ley n. ${ }^{\circ}$ 290, de 2011; artículo 41 del Decreto-Ley n. ${ }^{\circ}$ 292, de 2011; artículo 124 y Título x del Decreto-Ley n. ${ }^{\circ}$ 203, de 1999; artículo 43 del Decreto-Ley n. 228 , de 2002 .

24 Confróntese artículos 223.1 y 358.1 de la Ley n.o 7, de 1977.

25 Gordillo, A., Tratado de Derecho Administrativo, tomo 2 La defensa del usuario y del administrado, 8 ed., Buenos Aires, Fundación de Derecho Administrativo), 2006, p. 487.

26 Roselló Manzano, R., "El derecho de daños, la responsabilidad por producto y la protección de los consumidores”. Opinión Jurídica, vol. 8, n. ${ }^{\circ}$ 15, 2009, pp. 131-132.

27 Confróntese artículos 147 inciso g) y 175 de la Ley n. ${ }^{\circ} 116$, de 2013, así como artículo 702.1 de la Ley n. ${ }^{\circ}$, de 1977. 
EN BÚSQUEDA DE LA VOLUNTAS LEGISLATORIS: ACTOS DE COMPETENCIA DESLEAL CONTRA LOS CONSUMIDORES Y LEGITIMACIÓN PROCESAL DEL MINISTERIO PÚBLICO EN CUBA

productiva, comercial o de servicios en territorio nacional ${ }^{28}$. Además, el Consejo de Gobierno del Tribunal Supremo Popular dispuso similar tratamiento a los conflictos que involucren a trabajadores por cuenta propia ${ }^{29}$.

Finalmente, pudiera pensarse que la actio tutelae directa para los actos desleales sería la tipificación de alguno de los delitos del Código Penal, pero el autor aduce algunas razones en contra de este criterio. Las conductas punibles contenidas en el Capítulo viII "Infracción de las normas de protección de los consumidores" son insuficientes respecto a lo establecido en el Decreto-Ley n. ${ }^{\circ} 337$, pues este último recoge una mayor amplitud de comportamientos ilícitos. Los actos de competencia desleal del Decreto-Ley no necesariamente serán constitutivos de delito, ya que su configuración como tal dependerá de la peligrosidad social ${ }^{30}$. El Derecho penal debe ser la última de las opciones en el enfrentamiento a los procederes antijurídicos, debido a su entronizado carácter de ultima ratio.

Los desaciertos jurídicos e institucionales existentes en las normas atinentes al tema pueden derivar en un doble conocimiento de causas, confusión jurisdiccional de competencia en el conocimiento de actos de desleales en el comercio y vulneración de los derechos. Al mismo tiempo, desconecta hechos que según su naturaleza jurídica y los bienes comprometidos deben ser tratados en conjunto. La separación atendiendo el bien jurídico vulnerado, sea particular o colectivo es fútil, pues el uno repercute en el otro y viceversa. El reajuste de dicha escisión jurídica es necesario tanto para la protección de los consumidores como para precautelar los intereses de los operadores económicos que pueden ser perjudicados por la competencia desleal de otros.

La realización del proceso de investigación y resolución judicial en el campo de la competencia desleal debe unificarse y sancionarse por ambas aristas del fenómeno jurídico que atañe a la competencia desleal, ya sean bienes particulares o de la colectividad. Así se dota a los distintos actores económicos de seguridad jurídica y a los ciudadanos de acceder a bienes y servicios de calidad.

En cualesquiera de los casos la Fiscalía posee la legitimación otorgada por ley para intervenir en ellos. Por mandato constitucional es el órgano estatal cuya misión fundamental es ejercer el control de la investigación y el ejercicio de la acción penal pública en representación del Estado, así como velar por el estricto cumplimiento de las disposiciones normativas por los órganos, las entidades y los ciudadanos ${ }^{31}$. Son objetivos de este órgano procurar el restablecimiento de la legalidad cuando sea quebrantada por disposiciones o decisiones contrarias a la Constitución y las leyes o por aplicación indebida o incumplimiento de estas y proteger a los ciudadanos en el ejercicio legítimo de sus derechos e intereses.

28 Confróntese con artículos 739, 742, 746 incisos a), h) y j) de la Ley n.o 7, de 1977.

29 Consejo de Gobierno del Tribunal Supremo Popular de la República de Cuba. Instrucción n. ${ }^{\circ} 243$, de 2018.

30 Confróntese con los artículos 8.1.2 y 227.1 de la Ley n. ${ }^{\circ}$ 62, de 1987.

31 Confróntese con el artículo 156 de la Constitución de la República de Cuba de 2019. 
Para el logro de esas metas, tiene como funciones velar por el cumplimiento de las leyes por las personas; actuar ante violaciones de los derechos constitucionales y las garantías legalmente establecidas y frente a las infracciones de la legalidad en los actos de órganos estatales y entidades económicas, exigiendo su restablecimiento; atender las reclamaciones de los ciudadanos sobre presuntas violaciones de sus derechos; ejercer en representación del Estado las acciones judiciales que correspondan conforme a la legislación vigente, en función del interés social ${ }^{32}$.

A ese tipo de intervención en la doctrina se le denomina legitimación extraordinaria, pues permite a la Fiscalía esgrimir la pretensión aún sin poder afirmar la titularidad del derecho subjetivo. Villegas Oviedo plantea que "los supuestos de legitimación extraordinaria se han distinguido atendiendo al tipo de interés protegido por la disposición legal en la que se establece"33. Se le otorga a este órgano estatal una consideración especial por ley, dentro del proceso correspondiente, de manera que tendrá aptitud de ser parte. Luego, la vía permisiva de una participación efectiva del fiscal es la posibilidad otorgada por la ley procedimental de mostrarse parte cuando alegue un interés social ${ }^{34}$.

La ley rituaria dispone que los fiscales ejercitan las acciones civiles y promueven los actos y diligencias encomendados por ley a la Fiscalía, ejercen la representación procesal de la administración general del Estado ante los tribunales en los asuntos civiles en que deba ser parte sin necesidad de delegación y sin perjuicio de la facultad de aquella de hacer designación expresa cuando lo estime conveniente. El fiscal es parte en los procesos concernientes al estado civil, capacidad de las personas, cuando alegue un interés social y en todos aquellos previstos en la ley ${ }^{35}$.

Por tanto, la legitimación procesal según el Decreto-Ley n. 337 y las restantes normas de Propiedad Industrial es una llamada especial a la vocación tuitiva

32 Confróntese con el artículo 7, incisos a) y c), así como artículo 8, incisos a), b), c) y g) de la Ley n.o 83 , de 1997.

33 Villegas Oviedo, Y. de la C., "El fiscal en el proceso civil”, en Justicia y Derecho, año 11, n.o 20,2013 , p. 73 .

$34 \mathrm{El}$ interés social es una categoría jurídica sin despliegue doctrinal suficiente para entender su conceptualización en Cuba, siendo necesario acudir a las interpretaciones eventuales hechas por el Tribunal Supremo Popular. En el documento "Importancia del interés social y la racionalidad en las decisiones judiciales", de ese máximo órgano judicial, se plantea que el carácter popular de la justicia está definido por la forma en que los procesos y las decisiones adoptadas por ellos, contengan y reflejen en sí mismo el enfoque, las perspectivas y el punto de vista del pueblo, o sea, que en la actuación judicial prevalezca el interés social. También refiere que en el proceso de formación de la convicción, análisis, interpretación y toma de decisiones, debe considerarse que los jueces no actúan a título personal sino por mandato social; y será cumplido si se actúa de conformidad con los valores del pueblo, su idiosincrasia, inteligencia, entereza y sensibilidad. Algunas sentencias del Tribunal Supremo cubano hacen su propia interpretación de dichas indicaciones, por lo que se ha entendido como interés social casuísticamente a: el restablecimiento de la legalidad, la estabilidad jurídica, la seguridad jurídica y la voluntad de la mayoría de los ciudadanos. Véase de la Sala de lo Civil y lo Administrativo, Sentencia n. ${ }^{\circ} 314$, de 9 de abril de 2008; Sentencia n.o 1166, de 30 de noviembre de 2009, Primer Considerando; de la Sala de lo Económico, Sentencia n. ${ }^{\circ}$ 72, de 31 de octubre de 2011 y de la Sala de lo Penal, Sentencia n. ${ }^{\circ} 543$, de 20 de mayo de 2014.

35 Confróntese los artículos con 46 y 47 de la Ley n.o 7, de 1977. 
del fiscal. En esta perspectiva, el interés social se muestra como un interés plural, exponente de intereses colectivos y/o difusos, actuando el Ministerio Público como munera de esos intereses de la comunidad, que a él no le pertenecen sino a la sociedad, a sus individuos o a sus grupos. La doble naturaleza del Ministerio Fiscal como órgano del Estado-aparato y como órgano del Estado-comunidad queda evidenciada en estos casos. Es, esta, una naturaleza perfectamente acorde con la interacción sociedad-Estado definitoria de la forma en que el Estado social se relaciona con la sociedad ${ }^{36}$.

El Ministerio Público es invitado a participar en el procedimiento en defensa de la legalidad y tiene un papel relevante en la promoción de acciones colectivas para prohibir conductas contrarias al interés social ${ }^{37}$.

La intervención del Ministerio Fiscal responde, además, a la evidente dificultad que entraña el ejercicio de reclamaciones individuales por parte de los consumidores y a la irrenunciable necesidad de facilitarles el acceso a la tutela jurisdiccional en el marco de la economía procesal. La posición de estos sujetos en un litigio contra proveedores, aunque teórica y formalmente sea equivalente a la de estos últimos, no lo es en la práctica. La desigualdad y el desequilibrio de medios existentes entre ambas partes, una de las cuales goza habitualmente de mayor poder económico, constituye una de las razones justificativas de la intervención del Ministerio Público en defensa del interés social eventualmente comprometido.

Así pues, y sin perjuicio de la tutela individual, existe una tutela superior o colectiva de los derechos, superadora del modelo de legitimación en favor de quien afirma la titularidad de un derecho propio o de quien actúa en sustitución o representación del titular. En cualquier caso, los intereses supraindividuales suponen situaciones jurídicas materiales cuyos titulares no son las personas en su particularidad, sino en cuanto miembros, determinados o indeterminados, de una colectividad.

Dada la amplitud de jurisdicciones y sujetos intervinientes, deviene necesario consolidar criterios, establecer pautas mínimas de actuación y coordinación y determinar qué situaciones debe el fiscal atender especialmente. El ámbito penal es excluido de la presente investigación, pues sus particularidades inciden de una manera distinta en el actuar del Ministerio Público.

36 Fernández Le Gal, A., "La intervención del ministerio fiscal en defensa del interés público en procesos no penales. Especial atención a su labor de promoción y defensa del interés social y los derechos de los ciudadanos", en Revista Jurídica de los Derechos Sociales, vol. 4, n.o 1, 2014, p. 113.

37 Gómez Rodríguez, J. M., "La contribución de las acciones colectivas al desarrollo regional desde la perspectiva del derecho social", en Cuestiones Constitucionales Revista Mexicana de Derecho Constitucional, n. ${ }^{\circ} 30,2014$, p. 70. 
IV. ANÁLISIS SOBRE LA VÍA PROCESAL

PARA CONTRARRESTAR LA COMPETENCIA DESLEAL

Fundamentalmente, existen dos vías por las cuales la Fiscalía puede conocer la existencia de supuestos actos de competencia desleal o sus efectos: la Dirección de Verificaciones Fiscales y la Dirección de Atención al Ciudadano.

\section{A) El Sistema de Verificaciones fiscales}

El sistema de verificaciones fiscales abarca las acciones investigativas y diligencias necesarias con el auxilio de especialistas, para comprobar el cumplimiento de las disposiciones jurídicas vigentes. Su ejecución se realiza en los organismos estatales y entidades socioeconómicas con la finalidad de comprobar el cumplimiento de las disposiciones referidas al objeto social, uso, disponibilidad y destino de los recursos materiales y financieros y para la protección del capital social y bienes del Estado, a los efectos de prevenir, descubrir y enfrentar las manifestaciones delictivas. Permite descifrar los factores que intercedieron en la deformación conductual de los directivos y la utilización indebida de los recursos asignados. Posteriormente evalúa la efectividad de las medidas adoptadas al interior de las entidades. En la metodología para la ejecución de las verificaciones fiscales, se especifican con amplitud los objetivos de las mismas y se detalla el procedimiento a seguir para su realización. Esta señala que, en función de garantizar la efectividad de la labor del fiscal en el desarrollo de la verificación, debe tener: dominio técnico-jurídico de las normas a comprobar, objetividad y sistematicidad en su ejecución.

Por tanto, son objetivos de las verificaciones fiscales: comprobar el cumplimiento de las disposiciones referidas al objeto social; el uso, destino y preservación de los recursos materiales y financieros, así como de los sistemas de control establecidos; contribuir a la protección de los bienes de propiedad del Estado, velando porque se utilicen de acuerdo con los fines para los que fueron destinados y producidos; velar por el uso del capital social del Estado en las entidades jurídicamente privadas en las que tenga participación; prevenir, discutir y enfrentar las manifestaciones de corrupción administrativa; detectar posibles violaciones que puedan originar afectación a la salud o atenten contra las medidas de protección e higiene, la adecuada conservación del medioambiente y la explotación sostenible de los recursos naturales; contribuir a fortalecer la disciplina estatal, determinar la responsabilidad laboral, material o penal de los infractores de la ley en los casos que así se compruebe y demostrar y exigir la erradicación de las violaciones detectadas.

Este procedimiento contribuye a fortalecer la disciplina, determina el tipo de responsabilidad de los infractores de la ley y exige la erradicación de las violaciones detectadas. Por su carácter preventivo y educativo en el ámbito empresarial, constituye un mecanismo alternativo a la punición penal. No se puede esperar a que fenómenos sociales como el delito y la corrupción formen parte de la cotidia- 
EN BÚSQUEDA DE LA VOLUNTAS LEGISLATORIS: ACTOS DE COMPETENCIA DESLEAL CONTRA LOS CONSUMIDORES Y LEGITIMACIÓN PROCESAL DEL MINISTERIO PÚBLICO EN CUBA

nidad. Es obligación constitucional de la Fiscalía reducirlos con el propósito de evitar impactos negativos en el desarrollo económico del país y para el bienestar de la población. En ocasiones pueden detectarse además violaciones administrativas y falta de rigor y control en documentos oficiales, quebrantando así las normas cubanas y lo establecido por la Contraloría General de la República en este sentido.

El fiscal en el proceso de investigación debe ser consciente de que algunas manifestaciones delictivas por su naturaleza son más proclives a servir de medio para la realización de actos de competencia desleal: revelación de secreto administrativo, de la producción o los servicios; abuso en el ejercicio del cargo o empleo; incumplimiento del deber de preservar bienes en entidades económicas; difusión ilegal y uso no autorizado de invento infracción de las normas de protección de los consumidores, falsificación de documentos, malversación y apropiación indebida por solo mencionar las más representativas. Además, la investigación debe incluir el control a los activos fijos, con énfasis en los intangibles debido a la interrelación de los mismos en la ejecución de competencia desleal ${ }^{38}$. Los activos fijos intangibles comprenden los bienes no materiales que se poseen por las entidades para llevar a cabo las actividades operativas. Su característica fundamental es que no adoptan forma corpórea y solo son visibles en el instrumento legal que justifica el derecho a su usufructo. Se registran solo si se ha tenido que pagar algún costo de adquisición o desarrollo para obtenerlos. En algunos casos se amortizan, lo que equivale a recuperar lo invertido mediante su absorción como costos o gastos. Incluyen, entre otros, patentes, marcas de fábricas, nombres comerciales, franquicias, propiedad intelectual, arrendamiento financiero con opción de compra, programas computacionales.

Como se observa, la complejidad de indagar sobre competencia desleal es notoria, y aún más, para la Fiscalía cubana que no posee experticia en esta área del conocimiento. En sentido general, el parlamento cubano le recomendó trabajar por erradicar las deficiencias que aún persisten en la realización de las verificaciones fiscales, garantizando la preparación previa de fiscales y especialistas; así como el empleo adecuado de la información preliminar que se dispone, para alcanzar una mayor eficacia en esta actividad ${ }^{39}$.

Por tanto, se requiere una especialización de los fiscales en esta temática. A ello pueden contribuir las Universidades, la Oficina Cubana de la Propiedad Industrial, el Ministerio de Comercio Interior, el Bufete Especializado LEX con sede en La Habana, la Fiscalía General de la República y el Tribunal Supremo Popular.

38 Los activos fijos intangibles son aquellos no cuantificables físicamente, pues carecen de materialidad o sustancia corpórea, y solo son visibles en el instrumento legal que justifica el derecho a su uso y disfrute. Producen o pueden producir un beneficio económico en períodos futuros e implican un derecho o privilegio que posibilita reducir los costos o mejorar la calidad de los servicios o productos. Confróntese con el párrafo 4 de la Resolución n. ${ }^{\circ} 3$ de 2018.

39 Acuerdo viII - 91 de 2017. 
A partir de la prioridad nacional a los asuntos económicos y la protección de los derechos ciudadanos, la estrategia nacional diseñada para la preparación y superación de los cuadros debiera incluir estas temáticas en sus preparaciones ${ }^{40}$. De esta manera se alcanzará mayor integralidad, calidad, celeridad y organización en la ejecución de las verificaciones fiscales sobre actos desleales en el comercio, especialmente en los sectores de mayor sensibilidad social e importancia para el país.

\section{в) El sistema de Atención al Ciudadano}

Por otra parte, el sistema de Atención al Ciudadano comprende dos procesos fundamentales de trabajo: la atención a través de la comparecencia personal, la línea telefónica única, el correo postal, la entrega de escritos, el correo electrónico, el portal web y otras formas que deban incorporarse; así como la tramitación de las quejas, peticiones, denuncias y reclamaciones. Esta sería una de las vías fundamentales y directas en la que los consumidores pudieran presentar inconformidades por supuestos actos de competencia desleal. A propósito, la Fiscal General Yamila Peña Ojeda, informó que en 2018 fueron realizadas más de 100 acciones de control para la protección de los consumidores. Sin embargo, hasta el momento de redactar el presente artículo todavía la Fiscalía no había radicado demandas ante los tribunales con motivo de actos de competencia desleal contrarios a los intereses de los consumidores.

Este autor señala que la actividad investigativa en este ámbito debe tener como premisa la inviolabilidad e imposibilidad de renuncia de los derechos del consumidor. Además, aunque la norma ministerial de comercio interior no otorga prioridades, sería oportuno atender con más énfasis las situaciones subjetivas que afectan a grupos vulnerables (personas con capacidad disminuida, niños, mujeres embarazadas y el adulto mayor) y condiciones objetivas, en atención a bienes o servicios de uso o consumo generalizado.

En el primer caso, la posición de desequilibrio de los consumidores y usuarios en el marco de la contratación de bienes y servicios se refuerza y es susceptible de generar abusos. La labor del fiscal entronca con la idea de posibilitar el acceso judicial a los individuos pertenecientes a tales colectivos cuando, en atención a sus circunstancias concretas, no sea posible utilizar otros medios que permitan reequilibrar la situación de indefensión. Así se enmarca en el principio constitucional de proporcionar un mecanismo eficaz de acceso a la tutela judicial en condiciones de igualdad a los ciudadanos.

Desde un punto de vista objetivo, determinados bienes o servicios tienen mayor relevancia que otros en la vida de cualquier persona, y se les considera "de primera necesidad”. Por el carácter y la importancia de los mismos en la situación personal y concreta de cada ciudadano son acreedores de un control y protección

40 Colectivo de autores, La Fiscalia: protagonistas e historia. La Habana, Sello Editorial Fiscalía de Cuba, 2018, p. 46. 
EN BÚSQUEDA DE LA VOLUNTAS LEGISLATORIS: ACTOS DE COMPETENCIA DESLEAL CONTRA LOS CONSUMIDORES Y LEGITIMACIÓN PROCESAL DEL MINISTERIO PÚBLICO EN CUBA

diferenciada. El fiscal debe ponderar cuidadosamente la situación y conocer la opinión del (los) ciudadano(s) afectado(s) para valorar la oportunidad de la misma en el marco de las correspondientes diligencias preprocesales.

Antes de iniciarse un proceso, el promovente podrá solicitar la práctica de algunas pruebas si existen elementos fundados de que la fuente de prueba sufrirá afectaciones si se espera al momento procesal oportuno. Esta práctica es conocida como actos preparatorios y está regulada por la Ley de trámites civiles de Cuba, con particular destaque para la obligación de indemnizar daños y perjuicios, a instancia del requirente, por la ocultación, resistencia, negativa o excusa injustificada del requerido ${ }^{41}$. En los casos de competencia desleal puede persuadir al demandado de colaborar con la eficacia del proceso y preservar aquellos medios probatorios, especialmente los de expresión temporal o efímera.

Distinto sería la adopción de medidas cautelares, las que constituyen una parte importante de la tutela jurisdiccional ${ }^{42}$ en el ejercicio de la acción y aparejan una evidente identificación de su objeto con el de la pretensión de fondo, y su anticipación en tal contexto. En general se pueden solicitar: el cese inmediato del acto, el embargo o retención de los productos relacionados con la infracción, restricciones en la exportación e importación de esos productos y cualquier otra medida orientada a garantizar la eficacia del proceso. Estas cauciones pueden pedirse antes, conjuntamente o con posterioridad al ejercicio de la acción; pero siempre acreditando la titularidad del derecho o licencia del mismo y presente pruebas que permitan presumir la comisión de la infracción o su inminencia, y que la demora en aplicar la medida causará un daño irreparable o mayor.

Ahora bien, no se pueden confundir las medidas cautelares por violación de un derecho de propiedad industrial con las acciones establecidas por el Decreto-Ley n. ${ }^{\circ}$ 337 sobre competencia desleal. Dichas acciones constituyen la pretensión objeto del proceso; por lo tanto, se formulan en la demanda y son su núcleo esencial. Las mismas están comprendidas por: cese del acto en ejecución y la prohibición de su reiteración, prohibición del acto si aún no se ha ejecutado y el apercibimiento de que en lo sucesivo se abstenga de realizar este u otros con el mismo propósito, declaración de la deslealtad del acto si la afectación creada por este subsiste,

41 Confróntese con el artículo 216 de la Ley n.o 7, de 1977.

42 Se ha llegado incluso a esgrimir erróneamente en sede judicial que el establecimiento de medidas cautelares crea confusión entre los competidores y facilita el desvío de la clientela. Al respecto, con sapiencia la Superintendencia de Industria y Comercio de Colombia consideró: "no resulta convincente la idoneidad de tal conducta para generar confusión haciendo pensar equivocadamente a los consumidores que el establecimiento de comercio, actividades o prestaciones mercantiles de la persona contra quien se dirigen las medidas cautelares sean aquellos del solicitante, o que entre ellos exista una relación económica o jurídica indicativa de un mismo origen empresarial, pues es una conducta que tiene lugar en estrados judiciales y no en el mercado". Véase Castell Borrero, L. A.; Cure Uribe, S.; Nieto Durán, A. M.; Pérez Roja, L. M. y Romero Orozco, M. T., Análisis jurisprudencial de las Sentencias en segunda instancia, sobre la competencia desleal en Colombia, Trabajo de investigación presentado para optar por el título de abogado, Pontificia Universidad Javeriana, Bogotá, Colombia, 2009, pp. 83-84. 
restablecimiento de la situación existente antes de que aconteciere la vulneración ocasionada por el acto desleal y la detención inmediata de los efectos producidos, rectificación de las informaciones engañosas, incorrectas o falsas y el resarcimiento por los daños y perjuicios ocasionados, si se comprueba dolo o culpa del comi$\operatorname{sor}^{43}$. Una medida cautelar, en principio, no puede dictarse contra terceros por lo que incluye protección para asegurar que los consumidores no sean afectados injustificadamente como consecuencia de la misma contra el proveedor infractor. Sin embargo, la aplicación de este tipo de medidas no solo tiene la capacidad de afectar a los intervinientes dentro del proceso, sino también al comercio, por lo que se requiere la mayor cautela posible para disminuir las secuelas negativas.

Por su parte, en el procedimiento económico se disponen de forma genérica otras medidas cautelares que resultan de aplicación al civil en virtud de la supletoriedad inversa, distintiva de esta institución jurídica en $\mathrm{Cuba}^{44}$. En la Ley procedimental no se prevén medidas específicas para los procesos en los que se ventilen acciones colectivas. La única particularidad manifestada en esta materia deriva de la acción ejercida y de la efectividad de la tutela perseguida. Por ejemplo, en las acciones de cesación o de prohibición de realizar un acto que se reputa desleal, la medida cautelar típica será la de cesar provisionalmente en esa actividad o de abstenerse temporalmente de llevarla a cabo ${ }^{45}$. Toro Ochoa admite la complejidad de la aplicación de medidas cautelares particularmente en los casos de competencia desleal por violación de normas, pues los derechos disputados involucran la cotidianidad de la actividad empresarial económica. Las altas sumas dinerarias comprometidas no llegan a reflejar el verdadero perjuicio que se puede causar con las cautelares ${ }^{46}$.

Del Decreto-Ley n. 337 se desprende la facultad del fiscal para accionar, requerir medidas cautelares, recurrir en forma autónoma, apelar incluso cuando las partes no lo hicieran, interactuar con los demás actores de la sociedad civil e institucional e incluso intermediar en los conflictos procurando soluciones alternativas a la controversial de la justicia ${ }^{47}$.

En tanto las acciones colectivas no pretenden proteger solo los derechos subjetivos de cada afectado por competencia desleal, no constituyen una simple acumulación de acciones individuales. Una cuestión diferente y laberíntica sería la multiplicidad de procesos si los consumidores perjudicados decidieran entablar demanda por separado y en territorios distintos, una situación que atentaría contra la tutela judicial efectiva. De ahí que el fiscal reconozca la posibilidad de la acu-

43 Confróntese el artículo 12 del Decreto-Ley n.o 337, de 2016.

44 Confróntese el artículo 803 de la Ley n.o 7, de 1977.

45 Ovalle Favela, J., "Acciones populares y acciones para la tutela de los intereses colectivos", Boletín Mexicano de Derecho Comparado, nueva serie, año 36, n. ${ }^{\circ} 107,2003$, p. 608 .

46 Toro OchoA, D. "Las medidas cautelares en los procesos de competencia desleal por violación de normas: un estudio comparado desde el Análisis Económico del Derecho", en Revista Con-texto, n.o 49, 2018, pp. 37-39.

47 Rico, J. P., “El ministerio público no penal. Nuevas fronteras de actuación”, en REDEA Derechos en acción, año 3, n. ${ }^{\circ}$ 6, 2017-2018, p. 244. 
EN BÚSQUEDA DE LA VOLUNTAS LEGISLATORIS: ACTOS DE COMPETENCIA DESLEAL CONTRA LOS CONSUMIDORES Y LEGITIMACIÓN PROCESAL DEL MINISTERIO PÚBLICO EN CUBA

mulación de acciones en litisconsorcio, que sería problemática si los interesados están dispersos, carecen de información suficiente o se desmarcan en cuanto a la estrategia común a seguir por la Fiscalía. Luego, no puede descartarse la excepción de litispendencia para prevenir fallos contradictorios.

$\mathrm{Al}$ interponer demanda por competencia desleal, el fiscal estará involucrado en asuntos de un manifiesto contenido económico y que únicamente la existencia de un perjuicio conduce a establecer la acción, de ahí que el autor coincide con la Dra. Vázquez De Alvaré cuando refiere que no es imperiosa la probanza de esa lesión. "En todo caso, debe configurarse una inversión de la carga de la prueba de forma tal que el demandado pruebe que no hubo deslealtad en su actuación" ${ }^{48}$. El autor reitera que la pretensión objeto del proceso estará constituida por las diferentes acciones reconocidas por el artículo 12.1 del Decreto-Ley n. ${ }^{\circ} 337$.

En un proceso de esta índole, a los perjudicados les resulta difícil acceder a las fuentes de prueba, que sin embargo se encuentran a completa disposición del demandado. Por tanto, ocurre una contraposición entre el principio de carga de prueba y el de igualdad procesal. El fiscal debe estar alerta de tal situación para evitar perjuicios a los consumidores. Como solución se reconoce que las acciones $\mathrm{u}$ omisiones de los proveedores determinantes de daños o perjuicios a los consumidores darán lugar a la responsabilidad de aquellos, a menos que se acredite el cumplimiento de las exigencias o requisitos reglamentarios establecidos y los demás cuidados que exige la naturaleza del producto o servicio.

El análisis del contrato, si existiere, entre proveedores y consumidores también puede arrojar como salida a esta problemática la inversión convencional de la carga de la prueba, en la que las partes fijan reglas concretas de distribución de esta carga con vistas a un futuro litigio. La voluntad concurrente de las partes expresada en una particularísima forma de distribuir las cargas probatorias facilita la actividad demostrativa en los posibles litigios, pues se supone que el criterio distributivo elegido se fundará en juicios de facilidad y disponibilidad probatoria del sujeto en quien se depositen tales cargas ${ }^{49}$. No obstante, en las relaciones comerciales donde existe un intercambio expedito de bienes y servicios y no media contrato escrito, la solución descrita previamente no tiene razón de ser.

Amén de los principios rectores de todo proceso, en el debate sobre actos de competencia desleal, al menos dos son torales: el in dubio pro consumidor y el de congruentia. Por una parte, en caso de dudas se interpreta a favor del débil jurídico que en estos casos es el consumidor. En cambio, la conformidad, entendida esta como la actitud asumida por el consumidor ante la prestación de un servicio o la adquisición de un producto, es una noción imprescindible. Cuando se verifica esa falta de aprobación pudiera proceder: primero, derecho a la reparación o sus-

48 Vázquez de Alvaré, D., La competencia desleal en el mercado cubano, $2^{a}$ ed., La Habana, Ediciones onBC, 2016, p. 37.

49 Mantecón Ramos, A., Cien problemas de la prueba judicial en lo civil, La Habana, Ediciones ONBC y Ciencias Sociales, 2014, pp. 39-40. 
titución; luego, la rebaja del precio o resolución, y finalmente, la responsabilidad por saneamiento.

Pero ¿̇cómo se prueba un acto competencia desleal en Cuba? Primero debe iniciarse en la caracterización del hecho en sí mismo y diferenciarlo del resto de las modalidades según el Decreto-Ley n. ${ }^{\circ} 337$. Si bien es cierto que en materia de derechos de los consumidores el deber de probar discurre con mayor fuerza hacia quien aparentemente está en mejores condiciones de hacerlo, no lo es menos que la autoridad del fiscal permite compensar el desequilibrio probatorio existente. Al ser un funcionario público se reviste de atribuciones superiores para la obtención de fuentes de prueba sobre los hechos controvertidos.

Para que una conducta sea considerada como desleal debe comprobarse, en síntesis, que existe una violación de una norma jurídica; que como consecuencia directa el demandado haya adquirido una ventaja competitiva relevante frente a sus competidores y que el demandado la haya hecho efectiva en el mercado ${ }^{50}$. A propósito, la ley de procedimientos civiles regula un conjunto de medios probatorios disponibles para las partes en conflicto: la confesión judicial, los documentos y libros, el dictamen de peritos, el reconocimiento judicial y reproducciones, los testigos y las presunciones.

En la confesión judicial y dado que en Cuba una gran parte de los productos y servicios son ofrecidos por empresas estatales, una especial mención merece el artículo 279. Según el precepto, en los procesos en que sea parte el Estado, sus órganos y organismos o las empresas estatales, no se les pedirá confesión. En su lugar, la parte contraria propondrá por escrito las preguntas, las cuales serán contestadas en informe por los funcionarios a quienes conciernan los hechos. De esta manera, la regulación de la confesión judicial puede contradecir el principio de transparencia y profesionalidad refrendado en el apartado Quinto, inciso c) de la Resolución n. ${ }^{\circ} 54$ de 2018.

Para esa disposición ministerial, los mecanismos, procedimientos y procesos de las acciones para la protección al consumidor, concebidos de forma ágil, objetiva y con un eficiente manejo de los recursos, resultan evidentes, claros y comprensibles para las partes. Si al respecto se pretendiera mediante confesión judicial obtener más información de una empresa estatal que es demandada en un proceso de

50 "Tampoco se advierte que en el caso se haya infringido el principio de igualdad. El actor no es muy claro ni preciso al fundar este agravio, limitándose a decir que la aplicación informática señalada se encuentra al alcance de cualquier persona sin regulación alguna, vulnerando la regulación que el propio Estado ha impuesto y la libertad de trabajo formal, así como la seguridad de los propios usuarios, mediante competencia desleal. Haciendo un esfuerzo interpretativo cabe suponer que alude a que tales plataformas eluden la tributación por sus servicios y eso hace desleal la competencia, sin que llegue a entenderse la alusión a la inseguridad de los usuarios. No hay ninguna prueba en el expediente de que eso sea efectivamente así y, de serlo, la solución del problema va por carriles bien diferentes al elegido por el actor". Véase Tribunal de lo ContenciosoAdministrativo de Uruguay, Sentencia n. ${ }^{\circ}$ 936, de 30 de noviembre de 2017, , [en línea], disponible en: www.tca.gub.uy/visornew.php?numero=936\&ano=2017 [consultado el 12 de abril de 2020]. 
competencia desleal por actos contra los consumidores, la Fiscalía tendría que conformarse con el informe emitido. Esta situación problémica representa una violación al Derecho del consumidor a participar en el intercambio de opiniones en los procesos de decisiones que los afecten. Por tanto, la Ley de Procedimiento ofrece una ventaja procesal a los proveedores estatales que convierte a la práctica de la prueba de confesión judicial en un ejercicio unidireccional e impersonal.

En cuanto a la práctica de la prueba documental, es preciso la observancia de lo preceptuado en los apartados 3 y 4 del artículo 3 del Decreto-Ley n. ${ }^{\circ} 337$ : "La información no divulgada que sea necesario proporcionar por quien la posea, a cualquier autoridad administrativa o judicial que así lo requiera, no se considera divulgada a terceros de manera contraria a los usos comerciales honestos. Las autoridades que se mencionan en el apartado anterior, en caso de procesos administrativos o judiciales, adoptan las medidas necesarias para prevenir la divulgación a terceros ajenos".

De este modo se asegura que la información no pueda ser divulgada y afecte comercialmente a quien la proporcione.

Uno de los efectos más significativos de los documentos es su valor probatorio en procesos jurisdiccionales a los fines de comprobar la realización o no de determinados hechos. La eficacia de la fuerza probatoria es mayor en los documentos públicos que en los privados, debido a la fe pública del sujeto que lo otorga. Así el documento público goza de autenticidad, es decir, tiene fuerza probatoria en su contenido. Sin embargo, para que un documento privado sea prueba plena en un proceso judicial, es necesario que el afectado lo reconozca.

En los litigios de competencia desleal pueden coexistir tanto documentos públicos como privados ${ }^{51}$, donde los proveedores se encuentran en una posición

51 "Que el motivo tercero del recurso, con amparo en el apartado 9 del artículo 630 de la Ley de Procedimiento Civil, Administrativo, Laboral y Económico debe prosperar, porque es cierto, conforme en el mismo se afirma, que las pruebas han sido valoradas con error que trasciende al fallo, pues la confesión judicial prestada por el demandado y las deposiciones de los testigos examinados, vistas en relación con el resultado de las pruebas de documentos aportadas al pleito, demuestran los pormenores en torno a la búsqueda de registros interferentes por la oficina competente, previa solicitud de inscripción por el actor que data del 4 de noviembre de 2010, examen sustantivo del que resultó el registro a su favor del lema comercial "Usted disfrute de su fiesta que yo me encargo del recuerdo" y, por ende, el derecho exclusivo de usar en el tráfico económico dicho signo distintivo, por lo que, admitido por el otrora demandado, en ocasión de responder las posiciones del pliego a cuyo tenor fue interrogado, que usó una tarjeta de promoción contentivo de lema casi idéntico al que registrara legalmente el impugnante para similares servicios, es obvio que se configura acto infractor del derecho de propiedad industrial sin necesidad de previa declaración, con mayor razón cuando consta el testimonio imparcial, preciso e indubitado de la funcionaria de la sección provincial de la Oficina Cubana de la Propiedad Industrial que, no obstante, lo requirió al respecto, y asevera que aquel le manifestó que aún le quedaban tarjetas de ese tipo y que una vez agotadas imprimiría otra con lema distinto, lo que denota su inconsecuente proceder, pues con independencia de que ya se configuraba el actuar infractor, venía obligado, no solo a cesar en el uso de las tarjetas que contenían ese lema, sino a retirar las que ya había distribuido, adoptando cualquier otra medida para esclarecer la confusión que generaba la existencia en el potencial mercado de signo sobre el que existía el derecho prioritario dimanado de la registración oficial, sin que sea dable atender lo que expuso 
privilegiada en relación con el material probatorio. Su deber procesal de colaboración se acentúa, al punto de atribuírsele una carga probatoria más rigurosa que a su contraparte. El fiscal en estos casos debe actuar con firmeza al impedir que los proveedores se nieguen a facilitar los documentos necesarios.

La complejidad es aún mayor cuando se trata de contratos verbales. La celebración de estos generalmente no está precedida de una negociación de las partes, ni se incorporan las exigencias del consumidor a algún documento probatorio de ellas. Lo común son los contratos "instantáneos", que se celebran de manera cotidiana en la vida de los consumidores, que eventualmente generan comprobantes de pago o justificante de su celebración.

Según el Decreto-Ley 304 "De la contratación económica", el contrato puede ser verbal o escrito. Como regla debe ser escrito, bien sea manuscrito, en forma documental impresa o en soporte electrónico, sin sujeción a otro tipo de formalidad, salvo las excepciones establecidas legalmente. Cuando las condiciones o características así lo aconsejen, las partes pueden concertar contratos verbales, observando en lo pertinente las reglas establecidas con carácter general para su concertación ${ }^{52}$. Partiendo de esta regulación, los bienes y servicios se consideran conformes al contrato concertado si es susceptible de servir a los usos a que habitualmente se destinan los mismos. Se trata de un efecto contractual de alcance práctico para el consumidor, que suponen su legitimidad para exigir al proveedor las prestaciones propias de cada bien o servicio, según su naturaleza. También pudiera reclamar todo aquello ofrecido o publicitado, aunque no esté en el contrato, como resultado de la integración contractual ${ }^{53}$.

Toda alegación de competencia desleal debe estar probada, y no es suficiente presentar documentación, resoluciones y estudios, ya que estos son algunos de los medios de prueba para el juzgador. También se puede practicar la prueba pericial, que es un medio de probanza indirecto y de carácter científico que le permite al tribunal apreciar y valorar determinadas cuestiones relacionadas con los hechos objeto de debate. Se logra con la obtención del correspondiente informe confeccionado por un especialista, que permite suplir la ignorancia en ciertos campos del

\footnotetext{
el no recurrente para desvirtuar tales afirmaciones, e infructuosamente intentó demostrar con testifical endeble, en cuanto a la incorporación a proyecto distinto, por corresponder a todas luces a período posterior, además de que su imprevisión generó que aún en fecha reciente, como resulta el mes de diciembre de 2012, un posible cliente recibió una de estas tarjetas en unidad comercial dedicada a celebraciones en que es común gestionar los servicios de fotografía, elementos de trascendente relevancia que han sido obviados por la Sala sentenciadora, lo que permite colegir que con desacierto apreció el material probatorio puesto a su disposición y, por tal razón, se estima el motivo bajo examen y, sin necesidad de analizar los otros propuestos, se acoge el recurso y se casa la sentencia interpelada". Véase Tribunal Supremo Popular de la República de Cuba, Sala de lo Civil y lo Administrativo, Sentencia n.o 519, 31 de octubre de 2013.

52 Decreto-Ley n. ${ }^{\circ} 304$, de 2012.

53 Para una explicación más detallada sobre la relación entre la responsabilidad contractual y la competencia desleal en Cuba puede consultarse VÁzquez de Alvaré, D., La competencia desleal en el mercado cubano, 2a ed., La Habana, Ediciones onbC, 2016, pp. 88-90.
} 
EN BÚSQUEDA DE LA VOLUNTAS LEGISLATORIS: ACTOS DE COMPETENCIA DESLEAL CONTRA LOS CONSUMIDORES Y LEGITIMACIÓN PROCESAL DEL MINISTERIO PÚBLICO EN CUBA

saber humano, por resultar útil y necesario para la solución del proceso. Como es un derecho de las partes proponer la participación de peritos, hay que precisar los puntos a dictaminar por el especialista.

Posteriormente, el tribunal debe emitir pronunciamiento sobre dicha prueba propuesta (objetividad, necesidad e importancia de la misma para la solución del asunto en dependencia de la preparación que tenga el tribunal en el campo de la ciencia de que se trate), designar al o a los peritos que dictaminarán en el caso, poner a disposición de los peritos los elementos suficientes que les permitan dictaminar y disponer la práctica de la prueba nuevamente con intervención de otros peritos ante casos de discordancia entre ellos. Luego, el fiscal puede proponer la conformación de un cuerpo de especialistas (equipo multidisciplinario) que asista al tribunal en esos procesos, en correspondencia con la interdisciplinariedad y la complejidad de los asuntos.

Sobre el tema, la Cámara Primera de lo Civil de la Primera Sección del Centro de San Salvador sentenció: "si se pretende mediante expertos probar la violación marcaria, deben estos tener la cualidad y capacidad de poner en evidencia técni$\mathrm{ca}$, que al exponerse los productos en el mercado pueden crear en el consumidor una confusión, de tal manera que puede existir un aprovechamiento ilícito de un distintivo en relación a otro que está inscrito y que supone ser el aceptado por su calidad y prestigio, configurándose una competencia desleal en términos de aprovechamiento de fama comercial de la marca (...) se trata de que se pruebe que quienes al final son los que eligen el producto por su marca, son los que se confundirían o se confunden entre ambas marcas y eso no se establece mediante un estudio basado en informes subjetivos, eso emerge del análisis objetivo de la convergencia en el mismo mercado de los productos que se distinguen por las marcas que se dicen en disputa porque una supone infringir a la otra" ${ }^{34}$.

Con este argumento, el mentado tribunal le resta valor probatorio al dictamen pericial y lo sustituye por el reconocimiento judicial que debe hacerse en el contexto fáctico donde interactúan los productos marcarios en disputa, una solución con la que el autor no está totalmente de acuerdo.

El juez, para poder desarrollar su función, además de los conocimientos jurídicos, debe auxiliarse de especialistas para conocer o apreciar algún hecho de influencia en el proceso. En el caso de actos de competencia desleal, es en extremo difícil que el juez posea la sapiencia necesaria para comprender todas las especificidades sobre lo que se litiga. De ahí que el examen del lugar de los hechos aportará menos elementos a la decisión final. Para Cuba y en una situación similar, la solución más

54 Véase Cámara Primera de lo Civil de la Primera Sección del Centro de San Salvador, Sentencia 140-54-CM2-2013, de 6 de enero de 2014, [en línea], disponible en: www. jurisprudencia.gob.sv/DocumentosBoveda/D/1/2010-2019/2014/.../A4C1A.PDF [consultado el 12 de abril de 2020]. 
justa sería asumir la práctica simultánea de ambas pruebas conforme a las reglas establecidas para cada una de ellas ${ }^{55}$.

Respecto a la prueba de testigos y la de presunciones, el autor no considera necesario realizar señalamientos, pues la competencia desleal no representa nuevas particularidades. Solo se permite destacar que, conforme al apartado 1 del artículo 328 , se deben evitar las declaraciones de los consumidores del mismo producto o servicio involucrado en la deslealtad comercial, porque dichos sujetos tendrán inevitablemente interés directo en el pleito.

\section{REFLEXIONES CONCLUSIVAS}

La legitimación procesal del Ministerio Público cubano en litigios sobre Propiedad Industrial no es algo nuevo. La ley le otorga la capacidad para intervenir cuando se vea afectado el interés social, una premisa reforzada con la previsión legal de proteger a los consumidores contra actos comerciales desleales. En ese sentido, la posibilidad para entablar demanda estará en correspondencia con la configuración de afectaciones a los consumidores en la comisión de acciones de confusión, engaño, comparación y promoción de ventas, según el Decreto-Ley n. 337 de 2018. Como se trata de un ámbito de actuación que sí le es totalmente novedoso, se exige la especialización del fiscal y la concepción de una estrategia de trabajo específica.

La voluntad del legislador del Decreto-Ley n. 337 de 2018 fue encuadrar la intervención del Ministerio Público en el mandato constitucional de velar por la legalidad, integrar al fiscal en el sistema de la propiedad industrial y ser consecuente con las normas jurídicas anteriores sobre el tema. De este modo se refuerza la participación del Estado como garante de las relaciones comerciales, en especial aquellas en las que se involucran derechos de propiedad industrial, se facilita la representación voluntaria del consumidor o conjunto de estos para entablar demandas colectivas, a la vez que equilibra la posición procesal frente al proveedor. El fiscal actuará para prevenir o corregir las distorsiones en el mercado, ya que este es regulado por el Estado cubano, pero en esa función se le plantea un reto en cuanto al cauce procedimental en los tribunales.

El Decreto-Ley n. 337 de 2018 elimina la vacatio legis para la represión de la competencia desleal en Cuba, pero su coexistencia con la Resolución 54 de ese mismo año también complejiza la protección efectiva y expedita al consumidor. El nuevo marco regulatorio de la competencia desleal en sede de la propiedad industrial abarca aspectos sustantivos a los que la materia adjetiva no acompaña debido al lapso que dista entre ambas normas jurídicas. La relación entre la materia sustantiva y adjetiva es desestructurada y desorienta al consumidor o su representante en la petición de reclamar por afectaciones a sus derechos. Tal y como está regulado en la Ley de Procedimiento Civil, Administrativo, Laboral y Económico, 
son varias las jurisdicciones competentes para juzgar la deslealtad comercial. La necesidad de una nueva ley procedimental requiere el establecimiento de un proceso diferenciado para estos actos.

\section{REFERENCIAS}

Arboleda, A. M, “Beneficios y perjuicios de la estrategia de imitación”, en Estudios Gerenciales, n. ${ }^{\circ}$ 30, 2014.

Bernet Páez, M. A., "El ámbito subjetivo de aplicación de la Ley de competencia desleal", en Ius et praxis, año 24, n. ${ }^{\circ} 2,2018$.

Bonachea García, A. E., La política de competencia en Cuba. Tratamiento doctrinal y legal, Trabajo de Diploma, Universidad Central Martha Abreu de Las Villas, Cuba, 2013.

Castell Borrero, L. A.; Cure Uribe, S.; Nieto Durán, A. M.; Pérez Roja, L. M. y Romero Orozco, M. T. Análisis jurisprudencial de las Sentencias en segunda instancia, sobre la competencia desleal en Colombia. Trabajo de investigación presentado para optar por el título de abogado, Pontificia Universidad Javeriana, Colombia, 2009.

Castellanos Rodríguez, R., Baute Rosales, M., Chang Ramírez, J. A., y Cantero Jiménez, I., "Compatibilidad y límites entre mercado y socialismo: reto teórico-práctico en la conceptualización y actualización del modelo económico cubano", en Revista Cientifica, Cultura, Comunicación y Desarrollo, vol. 5, n.o $1,2020$.

Colectivo de autores, La Fiscalía: protagonistas e historia, La Habana, Sello Editorial Fiscalía de Cuba, 2018.

Fernández Le GaL, A. "La intervención del ministerio fiscal en defensa del interés público en procesos no penales. Especial atención a su labor de promoción y defensa del interés social y los derechos de los ciudadanos", en Revista Jurídica de los Derechos Sociales, vol. 4, n. ${ }^{\circ}$ 1, 2014.

Gómez Rodríguez, J. M., "La contribución de las acciones colectivas al desarrollo regional desde la perspectiva del derecho social", en Cuestiones Constitucionales Revista Mexicana de Derecho Constitucional, n. ${ }^{\circ}$ 30, 2014.

Gordillo, A., Tratado de Derecho Administrativo, tomo 2 La defensa del usuario y del administrado, 8a ed., Buenos Aires, Fundación de Derecho Administrativo, 2006.

Inostroza SÁez, M., "El ilícito concurrencial general en la Ley No 20.169 sobre Competencia Desleal", en Ius et Praxis, año 23, n.o 1, 2017.

Mantecón Ramos, A., Cien problemas de la prueba judicial en lo civil, La Habana, Ediciones ONBC y Ciencias Sociales, 2014.

Negrete Doria, E. F., "Aspectos procesales de la competencia desleal”, en Justicia Juris, vol. 12, n. ${ }^{\circ}$ 1, 2016. 
Ovalle Favela, J., "Acciones populares y acciones para la tutela de los intereses colectivos", en Boletín Mexicano de Derecho Comparado, nueva serie año 36, n. ${ }^{\circ} 107,2003$.

Reveco Urzúa, R. y Padilla Parot, R., "Derecho de la libre competencia”, en Revista Chilena de Derecho Privado, n. ${ }^{\circ}$ 28, 2017.

Rico, J. P., "El ministerio público no penal. Nuevas fronteras de actuación", en REDEA Derechos en acción, año 3, n. ${ }^{\circ}$ 6, 2017-2018.

Roselló Manzano, R., "El derecho de daños, la responsabilidad por producto y la protección de los consumidores", en Opinión Jurídica, vol. 8, n. ${ }^{\circ}$ 15, 2009.

Tamames, R., Diccionario de Economía, Segunda edición (revisada), Madrid, Alianza Editorial,1989.

Toro OchoA, D., "Las medidas cautelares en los procesos de competencia desleal por violación de normas: un estudio comparado desde el Análisis Económico del Derecho", en Revista Con-texto, n. ${ }^{\circ}$ 49, 2018.

VÁzQuez de Alvaré, D., La competencia desleal en el mercado cubano, 2a edición, La Habana, Ediciones ONBC, 2016.

Verbic, F. у Oteiza, E., "La Corte Suprema argentina y la construcción del derecho constitucional a un debido proceso colectivo", en International Journal of Procedural Law, vol. 5, n. ${ }^{\circ}$ 1, 2015.

Villegas Oviedo, Y. de la C., "El fiscal en el proceso civil", en Justicia y Derecho, año 11, n. ${ }^{\circ} 20,2013$.

\section{NORMAS JURÍDicAS CITADAS}

Constitución de la República de Cuba, en Gaceta Oficial n. ${ }^{\circ} 5$ Extraordinaria de 10 de abril de 2019.

Ley n. ${ }^{\circ} 7$ "Ley de Procedimiento Civil, Administrativo, Laboral y Económico", de 19 de agosto de 1977, Ediciones OnBC, La Habana, 2015.

Ley n. ${ }^{\circ} 62$ "Código Penal", en Gaceta Oficial n. ${ }^{\circ} 3$ Especial, de 30 de diciembre de 1987, con última modificación hecha por el Decreto-Ley n. ${ }^{\circ} 310$ de 29 de mayo de 2013, en Gaceta Oficial n. ${ }^{\circ} 18$ de 25 junio de 2013.

Ley n. ${ }^{\circ} 83$ "Ley de la Fiscalía General de la República", de 11 de julio de 1997, en Gaceta Oficial n. 8 Extraordinaria de 14 de julio de 1997.

Ley n. ${ }^{\circ} 116$ "Código de Trabajo" de 20 de diciembre de 2013", en Gaceta Oficial n. ${ }^{\circ} 29$ Extraordinaria de 17 de junio de 2014.

Decreto-Ley n. ${ }^{\circ} 203$ "De las marcas y otros signos distintivos", de 24 de diciembre de 1999, en Gaceta Oficial n. ${ }^{\circ} 3$ Extraordinaria de 2 de mayo de 2000.

Decreto-Ley n. 228 "De las indicaciones geográficas", de 20 de febrero de 2002, en Gaceta Oficial n. ${ }^{\circ} 11$ Ordinaria de 22 de febrero de 2002.

Decreto-Ley n.o 290 "De las invenciones y dibujos y modelos industriales", de 20 de noviembre de 2011, en Gaceta Oficial n. ${ }^{\circ} 002$ de 1 de enero de 2012. 
Decreto-Ley n. 292 "De los esquemas de trazado de circuitos integrados", de 20 de noviembre de 2011, en Gaceta Oficial n. ${ }^{\circ} 002$ de 1 de enero de 2012.

Decreto-Ley n. 304 "De la contratación económica", de 17 de diciembre de 2012, en Gaceta Oficial n. 062 Ordinaria de 27 de diciembre de 2012.

Decreto-Ley n. ${ }^{\circ} 337$ "De la protección contra las prácticas desleales en materia de Propiedad Industrial", de 30 de junio de 2016, en Gaceta Oficial n. ${ }^{\circ} 40$ Extraordinaria de 10 de agosto de 2018.

Decreto n. 343 "Del Sistema de la Propiedad Industrial", de 28 de febrero de 2018, en Gaceta Oficial n. ${ }^{\circ} 40$ Extraordinaria de 10 de agosto de 2018.

Acuerdo n. ${ }^{\circ}$ VIII -91 de la Asamblea Nacional del Poder Popular, de 21 de diciembre de 2017, en Gaceta Oficial n. ${ }^{\circ} 21$ Extraordinaria de 14 de marzo de 2018.

Resolución n. ${ }^{\circ} 3$ del Ministerio de Finanzas y Precios, que aprueba la Norma Cubana de Contabilidad n. 8 "Activos Fijos Intangibles", de 9 de enero de 2018, en Gaceta Oficial n. 7 Ordinaria de 27 de marzo de 2018.

Resolución n. ${ }^{\circ} 54$ del Ministerio de Comercio Interior, Aprueba indicaciones para la organización y ejecución de la protección al consumidor en el sistema de comercio interno, de 20 de abril de 2018, en Gaceta Oficial n. 26 Extraordinaria de 4 de mayo de 2018.

Instrucción n. ${ }^{\circ} 243$ de 14 de diciembre de 2018 del Consejo de Gobierno del Tribunal Supremo Popular de la República de Cuba, en Gaceta Oficial n.o 2 Ordinaria, de 23 de enero de 2019.

\section{JURISPRUDENCIA CITADA}

Cámara Primera de lo Civil de la Primera Sección del Centro de San Salvador, Sentencia n. ${ }^{\circ}$ 140-54-CM2-2013, de 6 de enero de 2014. Disponible en: www. jurisprudencia.gob.sv/DocumentosBoveda/D/1/2010-2019/2014/.../A4C1A. PDF [consultado el 12 de abril de 2020].

Corte Constitucional de Colombia, Sentencia C-535/97, de 23 de octubre de 1997. Disponible en: http://www.corteconstitucional.gov.co/relatoria/1997/c-535-97. htm [consultado el 10 de abril de 2020].

Tribunal de lo Contencioso-Administrativo de Uruguay, Sentencia n. ${ }^{\circ} 936$, de 30 de noviembre de 2017. Disponible en: www.tca.gub.uy/visornew. php?numero=936\&ano=2017. [consultado el 12 de abril de 2020].

Tribunal Supremo de España, Sala de lo Civil, Sentencia n. ${ }^{\circ}$ 59, de 29 de enero de 2019. Disponible en: https://www.iberley.es/jurisprudencia/sentenciacivil-n-59-2019-ts-sala-civil-sec-1-rec-1514-2016-29-01-2019-47983956. [consultado el 14 de abril de 2020].

Tribunal Supremo Popular de la República de Cuba, Sala de lo Civil y lo Administrativo, Sentencia n. ${ }^{\circ}$ 314, de 9 de abril de 2008.

Tribunal Supremo Popular de la República de Cuba, Sala de lo Civil y lo Administrativo, Sentencia n. ${ }^{\circ} 1166$, de 30 de noviembre de 2009. 
Tribunal Supremo Popular de la República de Cuba, Sala de lo Económico, Sentencia n. ${ }^{\circ} 72$, de 31 de octubre de 2011.

Tribunal Supremo Popular de la República de Cuba, Sala de lo Civil y lo Administrativo, Sentencia n. ${ }^{\circ}$ 519, 31 de octubre de 2013.

Tribunal Supremo Popular de la República de Cuba, Sala de lo Penal, Sentencia n. ${ }^{\circ} 543$, de 20 de mayo de 2014. 